\title{
Belgian Society of Cardiology
}

Meeting of November 12th, 1950

J. Lequime, H. Denolin, and L. Jonnart: The Peripheral Arterio-Venous Fistula. Clinical and physiopathological study of four cases.

Four patients with a peripheral aríerio-venous fistula are studied. The cardiac output is increased and the Branhàm phenomenon is present in each case. The right intra-auricular pressure does not change whether the fistula be opened or closed. In two cases cardiac output changes have been noted when the position varied of the patients: this is explained by changes of the arterio-venous shunt. The authors discuss the Branham phenomenon which is not due to changes of pressure in the right auricle.

H. Denolin: The Functional Respiratory Tests and Their Use in Heart and Lung Diseases.

The author describes a series of functional tests which he utilizes at the moment. He recalls the respiratory reactions of a normal person during a physical effort and insists on the meaning of the coefficient of oxygen consumption. This coefficient increases as normally in certain congenital heart diseases such as intra-auricular septal defect and patent ductus arteriosus. On the other hand coefficient decreases in cardiopathies in which the pulmonary output is insufficient, that is to say in heart insufficiency or in congenital stenosis of the pulmonary artery (pure stenosis, Fallot disease, tricuspid atresia). In emphysem the evolution of the coefficient is normal; this is paradoxical and depends on the insufficient increase of the ventilation. The result of this is an increase of the oxygen debt in the arterial blood as shown by the oximeter. The debt which already exists at rest in chronic lung diseases can be shown by inhaling pure oxygen which increases the consumption of this gas and its saturation in the blood. The author puts the accent on the interest in measuring the oxygen debt which can only reflect the patient total capacity by the effort. He also underlines the importance of bronchospiro-metrical studies.

/. Ende $\tau$ lé, J. Desneux, and C. Manet: Cardiovascular Changes During the Antabus-Alcohol Test. Ten patients have been studied during the Antabus-Alcohol test. Mostly marked peripheral vasodilatation occurred with tachycardia and hypotension (predominantly diastolic). E.C.G. records showed low T-waves and depressed ST. This test should only be performed under medical supervision.

J. Coliin: Complete A-V block with patterns of varying intraventricular block. Electro- and vectocardiographical study of one case of complete a-v block with patterns of varying intraventricular block shows 1 . changes of ventricular complexes according to the beginning of each complex. This initial phase lasting from 0.02 to $0.05 \mathrm{sec}$, is unique when QRS is shorter than 0.12 sec, otherwise it shows two waves: one of them has a very gradual slope and locates the block. 2. the arithmetical average of the slopes in D I and D III of these initial phases is in direct proportion with the duration of the corre sponding QRS. $\quad$ C. M. Callebaut. 